\title{
Effects of High Temperature Treatment on the Sprouting and Elongation Rate of Asparagus Spears
}

\author{
Shin-ichi Watanabe ${ }^{1 *}$, Masanori Matsuo', Hiroaki Kitazawa ${ }^{2}$, Machiko Fukuda $^{3 * *}$, \\ Atsushi Yamasaki ${ }^{4 * * *}$ and Atsuko Uragami ${ }^{3}$
}

${ }^{1}$ Kurume Research Station, Kyushu Okinawa Agricultural Research Center, NARO, Kurume 839-8503, Japan

${ }^{2}$ Food Research Institute, NARO, Tsukuba 305-8642, Japan

${ }^{3}$ Institute of Vegetable and Floriculture Science, NARO, Tsukuba 305-8519, Japan

${ }^{4}$ Tohoku Agricultural Research Center, NARO, Morioka 020-0123, Japan

In this study, we investigated the effect of high temperature on spear sprouting and elongation in asparagus to explore new approaches to control the harvest period in asparagus production. Four-year-old rootstocks of ' $\mathrm{UC157}$ ' were grown in chambers in the dark at $30^{\circ} \mathrm{C}\left(30^{\circ} \mathrm{C}\right.$ treatment), $34^{\circ} \mathrm{C}\left(34^{\circ} \mathrm{C}\right.$ treatment), $38^{\circ} \mathrm{C}\left(38^{\circ} \mathrm{C}\right.$ treatment), and $42^{\circ} \mathrm{C}\left(42^{\circ} \mathrm{C}\right.$ treatment) for 14 days, and then at $25^{\circ} \mathrm{C}$ for 18 days. In the $42^{\circ} \mathrm{C}$ treatment, no spear sprouting was detected, and all rootstocks died. During the high temperature period, the number of sprouted spears was significantly lower in the $38^{\circ} \mathrm{C}$ treatment than in the $30^{\circ} \mathrm{C}$ treatment, whereas after the high temperature periods, the number was significantly higher in the $38^{\circ} \mathrm{C}$ treatment than in the $30^{\circ} \mathrm{C}$ and $34^{\circ} \mathrm{C}$ treatments. The total number of sprouted spears during and after the high temperature periods was not significantly different between the $30^{\circ} \mathrm{C}, 34^{\circ} \mathrm{C}$, and $38^{\circ} \mathrm{C}$ treatments. The elongation rate of the spears during the high temperature period was significantly lower in the $38^{\circ} \mathrm{C}$ treatment than in the $30^{\circ} \mathrm{C}$ and $34^{\circ} \mathrm{C}$ treatments, whereas there were no significant differences in the mean spear elongation rate after the three high temperature treatments. These results suggest that a temperature of $38^{\circ} \mathrm{C}$ can be used to control spear sprouting reversibly by its application and cancellation.

Key Words: Asparagus officinalis L., spear elongation rate, spear number, sprouting control.

\section{Introduction}

Asparagus (Asparagus officinalis L.) is a perennial plant belonging to the Asparagaceae family (APG III, 2009), and the young spears from its rhizomes are eaten as a vegetable in the human diet. The spear yield is determined by the sum of the spear number and their individual weight. Given that the market price of spears fluctuates depending on the season, profitability for farmers could be enhanced by artificially controlling spear sprouting - suppressing spear sprouting during the low price period, but enhancing it during the high price period.

Received; January 8, 2018. Accepted; October 9, 2018.

First Published Online in J-STAGE on November 15, 2018.

No conflicts of interest declared.

* Corresponding author (E-mail: shinwa@affrc.go.jp).

** Present address: Agriculture, Forestry and Fisheries Research Council, Chiyoda-ku, Tokyo 100-8950, Japan.

*** Present address: Kurume Research Station, Kyushu Okinawa Agricultural Research Center, NARO, Kurume 839-8503, Japan.
Sprouting and elongation of asparagus spears are affected by environmental conditions (Robb, 1984) such as soil moisture, gas environment, and temperature. Consequently, it was reported that the spear number decreases under drier soil conditions (Krug, 1998; Wilcox-Lee, 1987) and increases with irrigation (Roth and Gardner, 1990). Low concentrations of oxygen (Kitazawa et al., 2014) or high concentrations of carbon dioxide in combination with low oxygen (Kitazawa et al., 2016) suppress spear sprouting. There are many reports on the induction and breaking of dormancy by low temperature (Krug, 1996, 1999; Ku et al., 2007; Nie et al., 2016). Jishi and Araki (2013) reported that the harvest period of white asparagus can be extended by storage of rootstocks under snow mounds. Under high temperature conditions, the rate of spear elongation increased linearly with increasing temperature from approximately $10^{\circ} \mathrm{C}$ to $30^{\circ} \mathrm{C}$ (Clupepper and Moon, 1939; Kim et al., 1989), and the spear number increased as the temperature rose from $15^{\circ} \mathrm{C}$ to $25^{\circ} \mathrm{C}$ (Gąsecka et al., 2009). In a rootstock-planting forcing culture, 
dormancy of asparagus rootstocks induced by low temperature could be broken and spear sprouting facilitated by high temperature treatment from $26^{\circ} \mathrm{C}$ to $28^{\circ} \mathrm{C}$ (Yamaguchi and Maeda, 2015). In contrast, the number of sprouted spears and elongation rates decreased when rhizomes were exposed to $36^{\circ} \mathrm{C}$ as compared to those subjected to $33^{\circ} \mathrm{C}$ (Yen et al., 1996). It was also reported that at $35^{\circ} \mathrm{C}$, the spear elongation rate slightly decreased compared to that at lower temperatures, whereas at $40^{\circ} \mathrm{C}$ spears sprouted but did not elongate and eventually decayed (Kim et al., 1989). These past reports imply that spear sprouting can be controlled by commencing or terminating the exposure of plants to sub-lethal high temperatures. Determining the range of high temperatures and the effect on sprouting may be utilized to develop a new control technology for spear sprouting during the hot season or in warm areas when the use of low temperature (cooling) is cost-prohibitive and thus not feasible.

In this study, we investigated the effects of high temperature treatments on spear sprouting and elongation in asparagus to explore new approaches for controlling the harvest period in asparagus production.

\section{Materials and Methods}

The experiment was carried out at the Kurume Research Station, Kyushu Okinawa Agricultural Research Center, NARO. Asparagus 'UC157' plants were grown in black polyethylene pots of $30.5 \mathrm{~cm}$ diameter and $17.9 \mathrm{~L}$ volume (TO Polypot with side hole No. 12; Tokai Kasei Co. Ltd., Mino, Japan). The pots were filled with compost of mixed field soil and weather-beaten cedar bark (Tenryo Eco Bark; Hita Resources Development Cooperative Association, Hita, Japan) at a $1: 1(\mathrm{v} / \mathrm{v})$ ratio. Fertilization was conducted once a year at transplanting in the first year of the experiment, and in February and March starting from the second to the fourth year. Nitrogen, $\mathrm{P}_{2} \mathrm{O}_{5}$, and $\mathrm{K}_{2} \mathrm{O}$ were applied at a rate of $18.0 \mathrm{~g}, 16.2 \mathrm{~g}$, and $18.0 \mathrm{~g}$ per pot, respectively, using controlled release fertilizers (Eco-Long 424 [180 days type] and CDU S555; JCAM AGRI Co. Ltd., Tokyo, Japan), along with $60 \mathrm{~g}$ per pot of organic calcium fertilizer (Ryujo-kudoseruka No. 2; Urabe Sangyo Co. Ltd., Hiroshima, Japan). Irrigation was performed several times a day using online drippers at a flow rate of $2.0 \mathrm{~L} \cdot \mathrm{h}^{-1}$ (PCJ-LCNL dripper; Netafim Japan Co. Ltd., Tokyo, Japan). Four-year-old plants were used in the experiment.

To avoid the effect of dormancy induced by low temperature on spear sprouting, the experiment commenced in September, when the mean air temperature was higher than $20^{\circ} \mathrm{C}$. The ferns from the potted plants were cut just above the ground, and 8 pots containing 4 male and 4 female rootstocks each were placed in chambers at $30^{\circ} \mathrm{C}\left(30^{\circ} \mathrm{C}\right.$ treatment $), 34^{\circ} \mathrm{C}\left(34^{\circ} \mathrm{C}\right.$ treatment $), 38^{\circ} \mathrm{C}$ $\left(38^{\circ} \mathrm{C}\right.$ treatment $)$, or $42^{\circ} \mathrm{C}\left(42^{\circ} \mathrm{C}\right.$ treatment $)$ and grown in the dark for 14 days (the high temperature treatment period). As the elongation rate of the spears is not retarded at temperatures below $30^{\circ} \mathrm{C}$ (Clupepper and Moon, 1939; Kim et al., 1989), the $30^{\circ} \mathrm{C}$ treatment was used as a control. After 14 days, the temperature in all chambers was reduced to $25^{\circ} \mathrm{C}$ and the rootstocks were grown in the dark for 18 additional days. During the experiment, air humidity in the chambers was not controlled, and plants were irrigated by hand to ensure that the moisture tension of the compost at $10 \mathrm{~cm}$ soil depth was more than $-10 \mathrm{kPa}$. Air temperature of the chambers and compost temperature measured at $10 \mathrm{~cm}$ depth and $7 \mathrm{~cm}$ from the pot edge were recorded by data loggers (TR-71U; T\&D Co., Nagano, Japan) every $10 \mathrm{~min}$.

Spear sprouting was assessed every day during the experiment. The number of sprouted spears and their lengths were recorded daily along with the date and time of measurement. The length of each spear that was more than $15 \mathrm{~cm}$ by day 7 from the sprouting was measured, the date and time were recorded, and the spear was harvested. The same was repeated for spears that did not reach a length of $15 \mathrm{~cm}$ within the first 7 days from sprouting. The elongation rate of each spear per day was calculated by dividing the difference in spear length between the sprouting date and time and the harvesting date and time by the elapsed time between sprouting and harvesting. Basal major and minor axes of harvested spears were measured by digital vernier calipers (PC-15JN; Mitsutoyo Co., Kawasaki, Japan), and the basal cross-sectional area of the spears was calculated assuming that the cut end of the spears was an oval.

\section{Results}

In the $30^{\circ} \mathrm{C}, 38^{\circ} \mathrm{C}$, and $42^{\circ} \mathrm{C}$ treatments, the actual air temperature in each chamber and the compost temperature in the pots were very close to the set values (Fig. 1). The air temperature data in the $34^{\circ} \mathrm{C}$ treatment were not obtained because of a data logger malfunction. However, the measured compost temperature in the pots suggested that the air temperature was very close to the set value.

In the $42^{\circ} \mathrm{C}$ treatment, no spear sprouting was detected during and after the exposure to high temperature. After the experiment, we confirmed that all the rootstocks were dead and in a process of decay.

The daily progress of spear sprouting in the $38^{\circ} \mathrm{C}$ treatment compared to that in the $30^{\circ} \mathrm{C}$ and $34^{\circ} \mathrm{C}$ treatments was slower during the high temperature period, but higher after the high temperature period ended (Fig. 2A). The total number of sprouted spears during the high temperature period decreased as the temperature rose; it was significantly lower in the $38^{\circ} \mathrm{C}$ treatment than in the $30^{\circ} \mathrm{C}$ treatment (Table 1). After the high temperature period ended, their numbers increased becoming significantly higher in the $38^{\circ} \mathrm{C}$ treatment than in the $30^{\circ} \mathrm{C}$ and $34^{\circ} \mathrm{C}$ treatments. When the total number of spears that sprouted during and after the high 


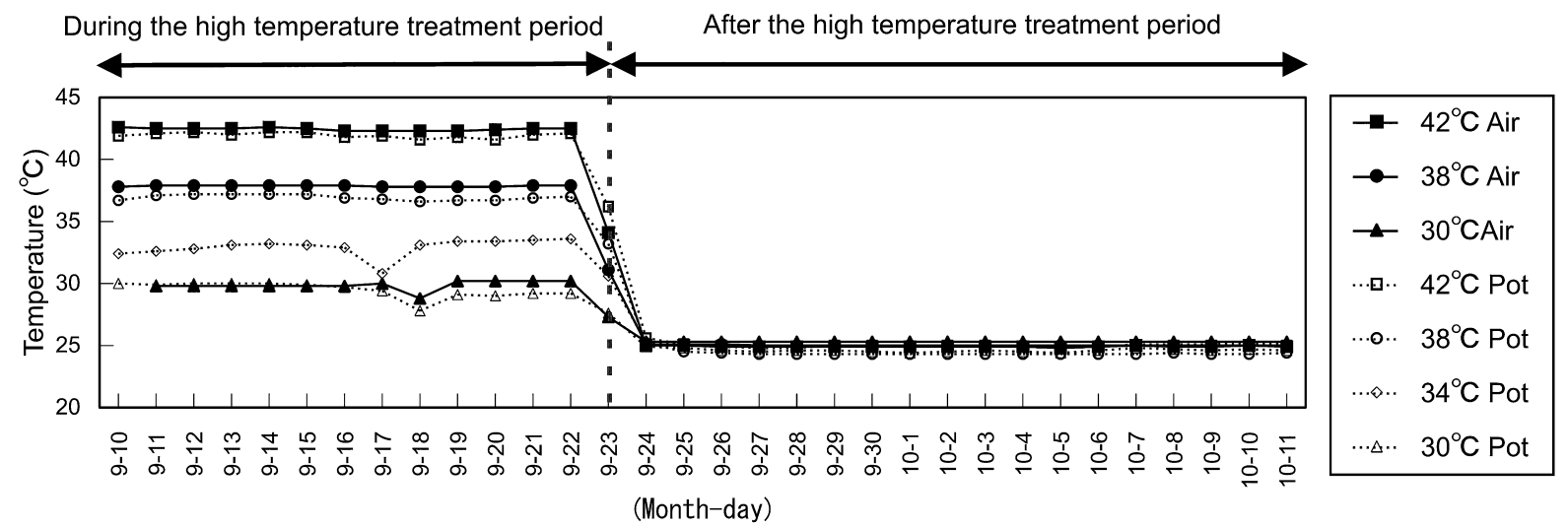

Fig. 1. Time course of the actual air temperature and compost temperature in a pot in treatments at $30^{\circ} \mathrm{C}, 34^{\circ} \mathrm{C}, 38^{\circ} \mathrm{C}$, and $42^{\circ} \mathrm{C}$. Air temperatures were set at $30^{\circ} \mathrm{C}, 34^{\circ} \mathrm{C}, 38^{\circ} \mathrm{C}$, or $42^{\circ} \mathrm{C}$ during the high temperature period, and reduced to $25^{\circ} \mathrm{C}$ after the high temperature period in all the treatments. Data pertaining to the air temperature were not obtained in the $34^{\circ} \mathrm{C}$ treatment due to malfunction of the data logger. Nevertheless, based on the compost temperatures in the pots in the same treatment, it was assumed that the air temperature was very similar to the set values.
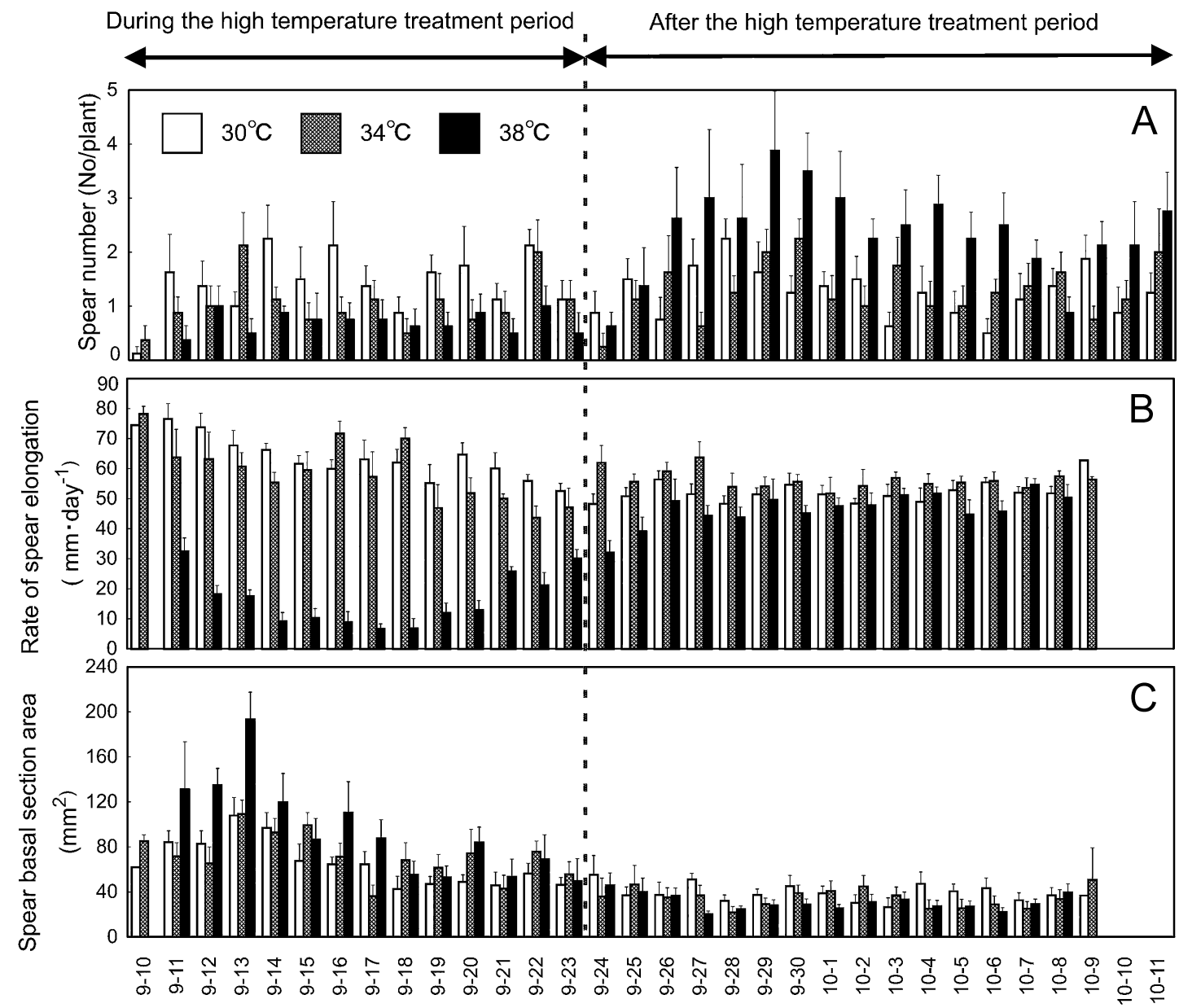

( Month - day)

Fig. 2. Effects of high temperature treatments on spear sprouting (A), elongation rate of the spears (B), and basal cross-section area of the spears (C). In B and C, data for 10-10 and 10-11 are lacking because the spears that sprouted on those days did not reach a length of $15 \mathrm{~cm}$ by the end of the experiment. The error bars represent the standard error.

temperature treatment were considered, there were no significant differences among these three treatments. There was no difference in the number of spears that sprouted during and after the high temperature periods in both the $30^{\circ} \mathrm{C}$ and $34^{\circ} \mathrm{C}$ treatments, whereas a significantly greater number of spears sprouted after the high 
Table 1. Effects of high temperature treatments on spear sprouting, spear elongation rate, and basal cross-section area of the spears during and after the high temperature treatment periods.

\begin{tabular}{|c|c|c|c|c|c|c|c|c|c|c|}
\hline \multirow{3}{*}{$\begin{array}{c}\begin{array}{c}\text { Temperature } \\
\left({ }^{\circ} \mathrm{C}\right)\end{array} \\
30\end{array}$} & \multicolumn{4}{|c|}{$\begin{array}{c}\text { No. of spears sprouting } \\
\text { (No./plant) }\end{array}$} & \multicolumn{3}{|c|}{$\begin{array}{l}\text { Elongation rate of spears } \\
\left(\mathrm{mm} \cdot \mathrm{day}^{-1}\right)\end{array}$} & \multicolumn{3}{|c|}{$\begin{array}{l}\text { Basal cross-sectional area of spears } \\
\left(\mathrm{mm}^{2}\right)\end{array}$} \\
\hline & \multirow{2}{*}{$\begin{array}{l}\text { During }^{\mathrm{y}} \\
20.0 \mathrm{a}^{\mathrm{u}}\end{array}$} & \multicolumn{2}{|c|}{ After $^{\mathrm{x}}$} & \multirow{2}{*}{$\frac{\text { Total }^{\mathrm{w}}}{38.8 \mathrm{a}}$} & \multirow{2}{*}{$\begin{array}{c}\text { During } \\
62.3 \mathrm{a}\end{array}$} & \multicolumn{2}{|c|}{ After } & \multirow{2}{*}{$\begin{array}{c}\text { During } \\
73.1 \mathrm{a}\end{array}$} & \multicolumn{2}{|c|}{ After } \\
\hline & & $14.6^{\mathrm{v}} \mathrm{b}$ & $\mathrm{NS}^{\mathrm{t}}$ & & & $50.7 \mathrm{a}$ & $* * *$ & & $40.3 \mathrm{a}$ & $* *$ \\
\hline 34 & $14.6 \mathrm{ab}$ & $15.2 \mathrm{~b}$ & NS & $34.1 \mathrm{a}$ & $54.8 \mathrm{a}$ & $54.4 \mathrm{a}$ & NS & $71.9 \mathrm{a}$ & $34.6 \mathrm{a}$ & $* * *$ \\
\hline 38 & $9.1 \mathrm{~b}$ & $27.8 \mathrm{a}$ & $* *$ & $44.9 \mathrm{a}$ & $13.5 \mathrm{~b}$ & $46.0 \mathrm{a}$ & $* * *$ & $100.8 \mathrm{a}$ & $33.2 \mathrm{a}$ & $* *$ \\
\hline
\end{tabular}

z Temperatures during the high temperature period.

y Values during the high temperature period.

$x$ Values after the high temperature period.

w Sum of the actual spear number during (14 days) and after (18 days) the high temperature period.

$\checkmark$ Values were adjusted to 14-day periods for statistical analyses of the results obtained during and after the high temperature treatments.

"Different letters in the same column indicate significant differences at the $5 \%$ level by Tukey's multiple range test $(\mathrm{n}=8)$.

t NS indicates no significance, $* * *$ and $* *$ indicate significance at $0.1 \%$ and $1 \%$, respectively, between the periods during and after the high temperature treatments by paired $t$-test $(\mathrm{n}=8)$.

temperature period than during the $38^{\circ} \mathrm{C}$ treatment (Table 1, Fig. 3).

The spear elongation rate was low in the $38^{\circ} \mathrm{C}$ treatment compared to that in the $30^{\circ} \mathrm{C}$ and $34^{\circ} \mathrm{C}$ treatments during the high temperature period, but it was comparable among these three treatments after the high temperature period (Fig. 2B). The mean elongation rate of the spears during the high temperature period was significantly lower in the $38^{\circ} \mathrm{C}$ treatment than in the $30^{\circ} \mathrm{C}$ and $34^{\circ} \mathrm{C}$ treatments, whereas there was no significant difference in the mean spear elongation rate after the high temperature period among the three treatments (Table 1). The mean spear elongation rate during the high temperature period as compared to that after the high temperature period was significantly higher in the $30^{\circ} \mathrm{C}$ treatment, but significantly lower in the $38^{\circ} \mathrm{C}$ treatment. In the $34^{\circ} \mathrm{C}$ treatment, there was no significant difference in the mean spear elongation rate between the two periods, during and after the high temperature treatment.

The basal cross-section area of the spears was not significantly different among the three treatments during and after the high temperature periods, although the basal cross-section area of the spears tended to be wider in the $38^{\circ} \mathrm{C}$ treatment than in the $30^{\circ} \mathrm{C}$ and $34^{\circ} \mathrm{C}$ treatments during the high temperature period (Fig. 2C). The basal cross-section area of the spears was significantly smaller after the high temperature period than during the exposure to high temperature in all treatments (Table 1).

\section{Discussion}

In this study, we present the possibility of controlling spear sprouting by using a high temperature such as $38^{\circ} \mathrm{C}$. Both the number of sprouted spears and the spear elongation rate tended to be significantly decreased in the $38^{\circ} \mathrm{C}$ treatment compared to those in the $30^{\circ} \mathrm{C}$ and $34^{\circ} \mathrm{C}$ treatments during the high temperature period. However, the number of sprouted spears was significantly increased, and the spear elongation rate ap-
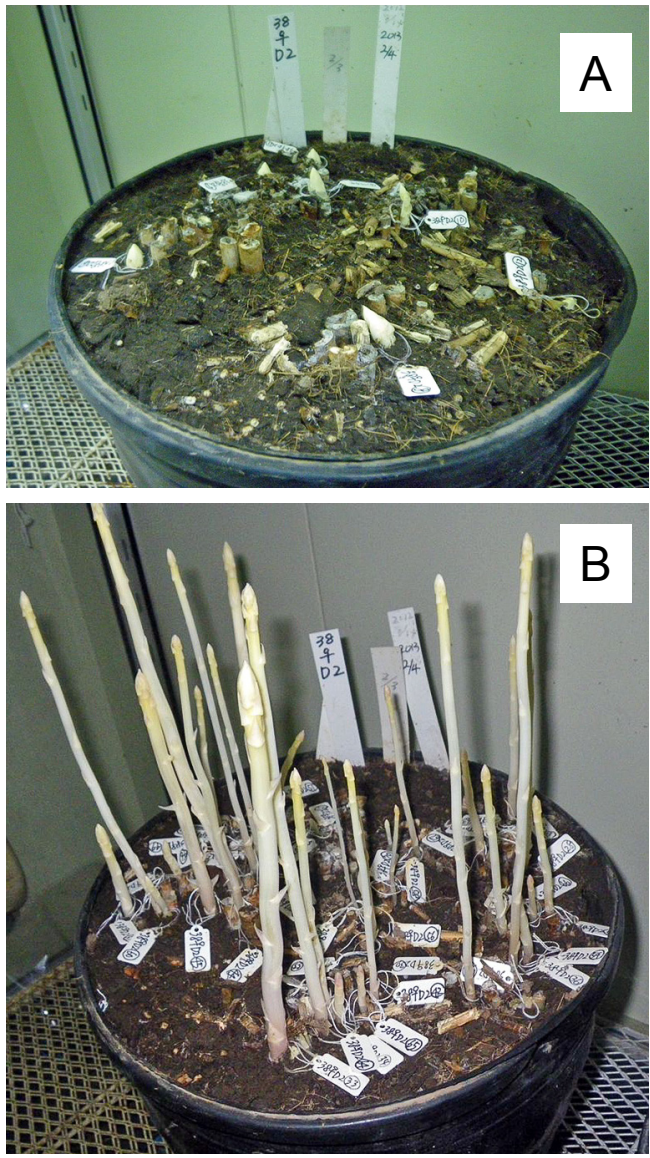

Fig. 3. Spear sprouting in the $38^{\circ} \mathrm{C}$ treatment during (A) and after (B) the high temperature treatments. The rootstock in A and B was the same. A, the rootstock at the end of the high temperature period; B, the rootstock 9 days after the high temperature period.

proached almost the same level as observed in the $30^{\circ} \mathrm{C}$ and $34^{\circ} \mathrm{C}$ treatments after the treatment period. These results showed that exposure of spears to a high temperature such as $38^{\circ} \mathrm{C}$ can be used to control spear sprouting reversibly. The detrimental effect of the $42^{\circ} \mathrm{C}$ treatment observed herein was similar to that reported 
in previous studies on asparagus spears that were exposed to $40^{\circ} \mathrm{C}$ (Kim et al., 1989). Taken together, these data indicate that asparagus rootstocks are unable to survive when exposed to a constant high temperature above $40^{\circ} \mathrm{C}$ for 5 days (Kim et al., 1989). In several crops, the base temperatures above which a physiological process stops (Tmax) and the lethal maximum temperatures (TLmax) were reviewed (Luo, 2007). For example, mean values \pm SEs of $T \max$ and $T L \max$ were above $20.9 \pm 0.2^{\circ} \mathrm{C}$ and $47.5 \pm 0.5^{\circ} \mathrm{C}$ in wheat (Porter and Gawith, 1999), $38.9 \pm 2.8^{\circ} \mathrm{C}$ and $46.0 \pm 2.9^{\circ} \mathrm{C}$ in maize, and $35.5 \pm 0.5^{\circ} \mathrm{C}$ and $42.9 \pm 0.7^{\circ} \mathrm{C}$ in rice (Sánchez et al., 2014). From the obtained results, the $T$ max and TLmax of asparagus seemed to be around $38^{\circ} \mathrm{C}$ and $40^{\circ} \mathrm{C}$, respectively, suggesting the difference between Tmax and TLmax is smaller in asparagus than those crops mentioned above. The factors that control for spear sprouting and elongation at high temperature should be taken into account to achieve both suppression of spear sprouting and prevent the plants from withering.

As the total number of sprouted spears during and after the high temperature periods showed no significant differences among the $30^{\circ} \mathrm{C}, 34^{\circ} \mathrm{C}$, and $38^{\circ} \mathrm{C}$ treatments, the buds for which sprouting was suppressed during the high temperature period were able to sprout after the high temperatures in the $38^{\circ} \mathrm{C}$ treatment were withdrawn. Moreover, sprouting numbers per day increased for about 10 days to fill the shortfalls during the treatment. This shows that it is possible to control the number of spears harvested, i.e., increasing the amount during the higher price period and decreasing the amount during lower price period in the market. In freesia, cormlets could be stored for more than 200 days under a high temperature condition at $30^{\circ} \mathrm{C}$ (Doi et al., 2001), and Leucocoryne bulbs could be stored for 12 weeks under a high temperature condition at 30 and $35^{\circ} \mathrm{C}$ (Nakatsuka et al., 2018). As the effect of $38^{\circ} \mathrm{C}$ was tested for a relatively short period of 14 days in this study, further studies are needed to investigate the suppression effect of $38^{\circ} \mathrm{C}$ for longer treatment periods.

Spear sprouting and elongation were significantly suppressed but not completely stopped in this study. It was reported that young asparagus plants have a developmental phase that prevents them from acquiring the dormancy characteristic (Yamaguchi and Maeda, 2016). It was also reported that the changes in abscisic acid (ABA) content in large and small crowns during a high temperature period at $38^{\circ} \mathrm{C}$ were different; the $\mathrm{ABA}$ content in large crowns decreased gradually whereas the content in small ones increased (Fukuda et al., 2017). As there were crowns (bulbils) of different ages and sizes in the 4-year-old asparagus plants used in this study, the obtained results may reflect differences in responsiveness to high temperature of individual crowns (bulbils).

As mentioned above, strict temperature control is needed to apply high temperature treatment to field cultivation because there is only a slight difference in temperatures that induce suppression of spear sprouting and those which result in plant death. With the application of high temperature treatment, an indoor spear production system during the harvest period (Watanabe et al., 2012a, b) could be promising because it is easy to control the temperature during the harvest period and it would be possible to regulate sprouting more strictly in combination with controlling the gas environment (Kitazawa et al., 2014, 2016). For production in plastic houses, although it is difficult to control temperature accurately in comparison with the indoor spear production system, applying localized temperature control systems such as the crown-temperature control technique developed for strawberries (Dan et al., 2015) would be useful. In addition, concomitant use with spear sprouting retarding factors such as adding extra mother ferns (Jinno, 2014) and/or decreasing soil moisture (Krug, 1998), could be promising techniques to suppress spear sprouting and elongation in plastic house production.

In this study, we concluded that a high temperature of $38^{\circ} \mathrm{C}$ can be implemented to control spear sprouting reversibly by its application and cancellation. The findings are expected to be used as a new approach to control the harvest period in asparagus production.

\section{Acknowledgements}

The authors thank Mrs. M. Nagamatsu, Mrs. Y. Oka, and the trainees of the Kurume Development Training Course for their research assistance.

\section{Literature Cited}

APG III. 2009. An update of the Angiosperm physiology group classification for the orders and families of flowering plants: APG III. Bot. J. Linn. Soc. 161: 105-121.

Clupepper, C. W. and H. H. Moon. 1939. Effect of temperature upon the rate of elongation of the stems of asparagus grown under field conditions. Plant Physiol. 14: 255-270.

Dan, K., W. Sugeno, S. Nakahara, N. Goto, Y. Iwasaki, I. Takano, M. Okimura, K. Hidaka, T. Takayama and H. Imamura. 2015. Experiment on the crown-temperature control technique in forcing culture of strawberries in Miyagi. Bull. NARO Kyushu Okinawa Agric. Res. Cent. 64: 1-11 (In Japanese with English abstract).

Doi, M., Y. Torata-Imamura, H. Maniwa and H. Imanishi. 2001. High temperature storage of freesia cormlets for delaying flowering time. J. Japan. Soc. Hort. Sci. 70: 740-746 (In Japanese with English abstract).

Fukuda, M., S. Matsuo, S. Watanabe and A. Uragami. 2017. Effect of incubation temperature on asparagus crown sprouting and abscisic acid content. Abstr. the 14th International Asparagus Symposium: 48.

Gąsecka, M., W. Krzesiński, J. Stachowiak and M. Knaflewski. 2009. The effect of temperature and crown size on asparagus yielding. Folia Hort. 21: 49-59.

Jinno, N. 2014. Effects of methods of additional mother stems in summer on spear yield and quality in half-forcing long-term crop cultivation of asparagus. Bull. Nagasaki Agr. For. Tech. Dev. Cent. 5: 21-25 (In Japanese with English abstract). 
Jishi, T. and H. Araki. 2013. Effects of long-term storage of oneyear-old rootstocks in snow mound on the sugar contents of storage roots and white spear yield of asparagus. J. Japan Soc. Hort. Sci. 82: 138-144.

Kim, Y. S., R. Sakiyama and A. Tazuke. 1989. Effect of temperature on the elongation rate and the estimation of weight of asparagus spears. J. Japan. Soc. Hort. Sci. 58: 155-160 (In Japanese with English abstract).

Kitazawa, H., N. Hasegawa, M. Fukuda, S. Watanabe, A. Yamasaki and A. Uragami. 2014. Changing oxygen concentration around the rootstock alters spear elongation and sprouting of white asparagus. Sci. Hortic. 178: 211-216.

Kitazawa, H., N. Hasegawa, M. Nagata, M. Fukuda, S. Watanabe, A. Yamasaki and A. Uragami. 2016. Combination of low oxygen and high carbon dioxide treatments alters sprouting of white asparagus. Turk. J. Agric. For. 40: 450-455.

Krug, H. 1996. Seasonal growth and development of asparagus (Asparagus officinalis L.). I. Temperature experiments in controlled environments. Gartenbauwissenschaft. 61: 18-25.

Krug, H. 1998. Seasonal growth and development of asparagus (Asparagus officinalis L.). II. Influence of drought on crown activity. Gartenbauwissenschaft. 63: 71-78.

Krug, H. 1999. Seasonal growth and development of asparagus (Asparagus officinalis L.). IV. Crown activity as a function of incubation temperature and temperature gradient. Gartenbauwissenschaft. 64: 84-88.

Ku, Y. G., D. J. Woolley, A. R. Hughes and M. A. Nichols. 2007. Temperature effects on dormancy, bud break and spear growth in asparagus (Asparagus officinalis L.). J. Hortic. Sci. Biotech. 82: 446-450.

Luo, Q. 2007. Temperature thresholds and crop production: a review. Climatic Change. 109: 583-598.

Nakatsuka, T., M. Ide, R. Omiya and H. Ohno. 2018. Effect of storage temperature and its period on bud emergence and flowering of Leucocoryne bulbs. Hort. Res. (Japan). 17: 211-217 (In Japanese with English abstract).

Nie, L. C., Y. H. Chen and M. Liu. 2016. Effects of low tempera- ture and chilling duration on bud break and changes of endogenous hormones of asparagus. Eur. J. Hortic. Sci. 81: $22-26$.

Porter, J. R. and M. Gawith. 1999. Temperatures and the growth and development of wheat: a review. Eur. J. Agron. 10: 2336.

Robb, A. R. 1984. Physiology of asparagus (Asparagus officinalis) as related to the production of the crop. New Zeal. J. Exp. Agr. 12: 251-260.

Roth, R. L. and B. R. Gardner. 1990. Asparagus spear size distribution and earliness as affected by water and nitrogen applications. Trans. Amer. Soc. Agr. Eng. 33: 480-486.

Sánchez, B., A. Rasmussen and J. R. Porter. 2014. Temperatures and the growth and development of maize and rice: a review. Glob. Chang. Biol. 20: 408-417.

Watanabe, S., S. Furuya and Y. Yamato. 2012a. Effects of dry and cool treatments on Brix of storage roots and spear yield during autumn and winter seasons of two-year-old crowns grown with pots. Hort. Res. (Japan) 11 (Suppl. 2): 462 (In Japanese).

Watanabe, S., S. Furuya, Y. Yamato and H. Ikeda. 2012b. Spear productivity of two-year-old crowns grown with pots during autumn and winter seasons. Hort. Res. (Japan) 11 (Suppl. 1): 118 (In Japanese).

Wilcox-Lee, D. 1987. Soil matric potential, plant water relations, and growth in asparagus. HortScience. 22: 22-24.

Yamaguchi, T. and T. Maeda. 2015. Effect of high-temperature treatments on the breaking of dormancy in one-year-old asparagus (Asparagus officinalis L.). Environ. Control Biol. 53: 23-26.

Yamaguchi, T. and T. Maeda. 2016. Developmental phase incapable of dormancy induction in young asparagus (Asparagus officinalis L.) plants. Hort. Res. (Japan). 15: 67-72 (In Japanese with English abstract).

Yen, Y. F., M. A. Nichols and D. J. Woolley. 1996. Growth of asparagus spears and ferns at high temperature. Acta Hort. 415: 163-174. 